\title{
Simulation of thermal treatment of mineral wool blanket
}

\author{
Anton Pilipenko ${ }^{1, *}$, Ekaterina Bobrova ${ }^{2}$, and Boris Efimov ${ }^{1}$ \\ ${ }^{1}$ NRU Moscow State University of Civil Engineering, Yaroslavskoye shosse, 26, Moscow, Russia \\ ${ }^{2}$ NRU Higher School of Economics, Myasnitskaya st., 20, Moscow, Russia
}

\begin{abstract}
This article describes results of modelling of heat treatment of mineral wool blanket. The properties of mineral wool products are largely determined by the conditions of heat treatment, which is carried out by suction of the heat carrying agent through a layer of mineral wool blanket. The choice of technological parameters and optimization solutions determines both the energy costs of manufacturing mineral wool products and their properties and the stability of these properties over time when used in structures. Optimizing the heat treatment parameters of a mineral wool blanket is a labor-intensive and time-consuming task. The development of accelerated methods based on the analysis of the results of previously conducted and new studies can significantly reduce the time for choosing technological parameters, as well as increase the reliability and adequacy of decisions.
\end{abstract}

\section{Introduction}

The current level of technological development, including the construction industry, shows the interconnection of energy efficiency and environmental sustainability, which become the criteria for modern innovative development of the Russian economy. In the field of construction technologies, the issues of energy conservation, environmental protection, optimization of energy costs in the production and use of building materials, increasing the operational resistance of materials, and, consequently, the durability of structures have become very relevant [1-4].

One of the ways to solve these problems was the introduction of building systems based on the use of effective heat-insulating materials. The most widely used group of thermal insulation materials are mineral wool products. Most of these products are non-combustible (NG group according to GOST standards) or belong to the G1 group; have low density and thermal conductivity [5-8].

At the same time, the stability of properties and the operational stability of products from mineral wool are largely determined as features of the technology of their manufacture, properties of mineral fibers. Mineral fiber products are made on a synthetic binder, inherently two-component, and in the case of the use of a water repellent agent - three-component. The

\footnotetext{
*Corresponding author. pilipenko.ans@gmail.com
} 
final properties of the products depend on the interaction of these components (without taking into account the synergetic effects of this interaction) [9-12].

First of all, the properties of products are determined by the uniform distribution in the mineral wool blanket and curing of the binder, as well as parameters and conditions of its heat treatment. Monitoring of existing plants showed that the main problems of creation of products from mineral wool are incomplete polycondensation of the binder in the material, uneven curing of the binder in the area and thickness of the mineral wool blanket, and energy overrun for heat treatment of the blanket. The periodic occurrence of force majeure due to the ignition of a mineral wool blanket in heat treatment chambers should be also noted.

\section{Experimental}

To optimize the parameters of heat treatment of mineral wool blanket, increase the uniformity of its heating and minimize technological errors, studies were conducted. The main task was to identify the main dependences of the heat carrying agent passing through the matrix of the mineral wool blanket and to construct a mathematical model based on experimental data.

The mineral wool blanket was heat treated by suction of the heat carrier (air heated to $200-240^{\circ} \mathrm{C}$ ) through the blanket layer. In this case, moisture is evaporated from the blanket and the binder is cured [13-16]. The purpose of the heat treatment is to stabilize the structure of the blanket by curing the binder, which occurs as a result of polycondensation reactions. Factors such as replacing mesh conveyors with lamellar conveyors and changing the density of a mineral wool blanket have a significant effect on the aerodynamics of heat treatment. This must be taken into account when designing the design and operating modes of the camera.

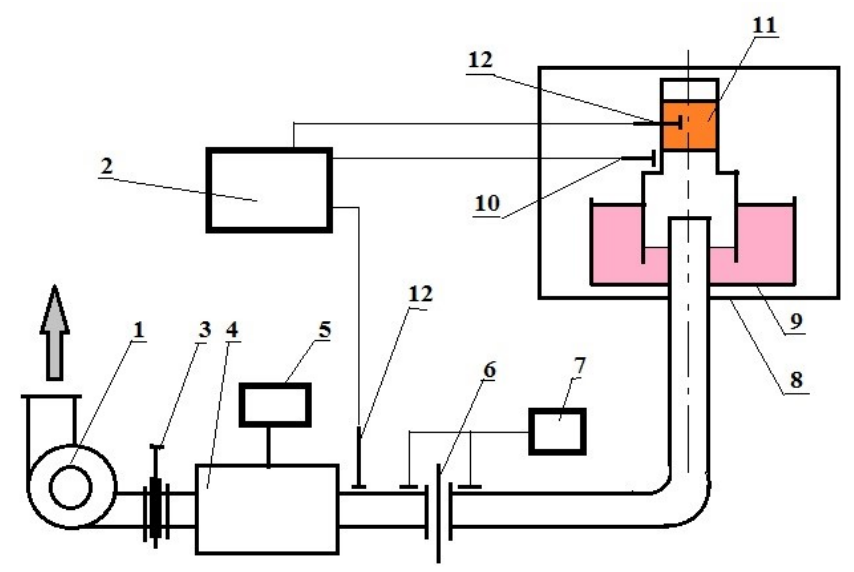

Fig. 1. Scheme of the experimental flow stand: 1 - fan; 2 - measuring unit; 3 - gate; 4 - electric heater; 5 - voltage regulator; 6 - throttle aperture; 7 - micromanometer; 8 - camera; 9 - water seal; 10 differential pressure gauge; 11 - clip with a multi-wool sample; 12 - thermocouples.

Mineral wool blanket is a porous material consisting of thin fibers of a glassy structure, obtained from a melt of rocks and their compositions, slags or glass mixture. Mineral wool and products from it belong in their structure to the group of capillary-porous fibrous materials with randomly distributed fibers [17-20].

Mineral wool blanket is not a homogeneous material and has anisotropic properties. The spatial framework of the mineral wool blanket consists of randomly arranged fibers. The diameter of the fibers, depending on the method of fiber formation, is 3-8 microns, and the length is up to $50 \mathrm{~mm}$. Non-fibrous inclusions up to $0.1 \mathrm{~mm}$ in size can be found in a mineral 
wool blanket [21-23]. The formation of a mineral-cotton blanket from arbitrarily arranged thin fibers determines a highly developed inner surface reaching $30000 \mathrm{~m}^{2} / \mathrm{m}^{3}$ and porosity up to $97 \%$. These factors ensure the efficiency of heat treatment by blowing the heat carrier through a layer of mineral wool blanket. The study of the main parameters characterizing the heat treatment process was carried out on a purge stand, the schematic diagram of which is shown in Fig. 1.

The air from a test room, heated in an electric heater to the desired temperature, was used as heat carrying agent. The required flow rate of the heat carrying agent was established and recorded using a gate with a micromanometer. The change in temperature of the material and heat carrying agent was measured with thermocouples and recorded with two electronic potentiometers included in the measuring unit of the stand. During the experiments, mineral wool samples were placed in a holder, the shape and dimensions of which were changed depending on the type of experiments being conducted.

\section{Results}

A study of the processes taking place in a mineral wool blanket shows that its hydraulic resistance is directly proportional to the surface of the fibers per unit volume of the layer and inversely proportional to the third degree of porosity of the layer. The established degree of influence of the fiber diameter on the hydraulic resistance of the mineral wool layer is shown in Fig. 2.

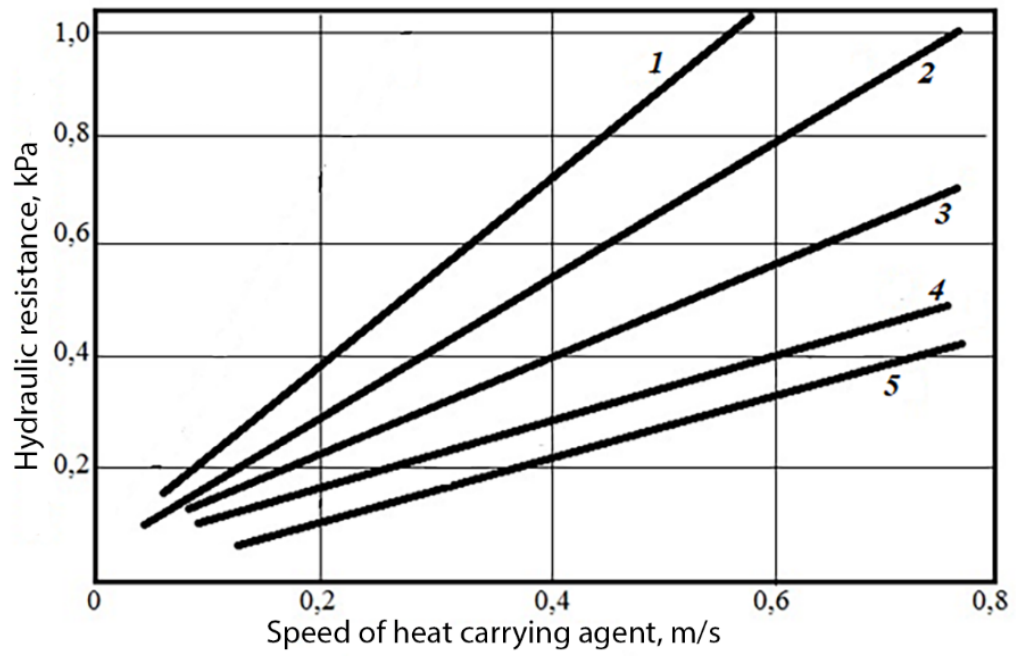

Fig. 2. The dependence of the hydraulic resistance of a mineral wool blanket with a thickness of 50 $\mathrm{mm}$ on the speed of heat carrying agent with a thickness of mineral fiber, microns: 1) $-8 ; 2)-7$; 3 ) -6 ; 4$)-5$; 5) -4 .

Analysis of data on mineral fibers (and products based on them) allowed us to draw the following conclusions:

- the specific surface of the layer has a linear dependence on its average density,

- the hydraulic resistance of the layer will be greater, the smaller the number of slugs and the smaller the diameter of the fibers.

Experimental data confirmed this assumption. At a flow speed of $0.4 \mathrm{~m} / \mathrm{s}$, the hydraulic resistance of semi-rigid plates with an average density of $91 \mathrm{~kg} / \mathrm{m}^{3}$ is $350 \mathrm{~Pa}$. An analysis of the experimental data and the calculation results shows that the hydraulic resistance of the layer depending on the fiber diameter $\left(\mathrm{d}_{\mathrm{v}}\right)$, the content of non-fibrous inclusions (slugs etc.) 
$(\mathrm{X})$, the flow speed (v), the average density $(\rho)$, and the thickness $(\mathrm{H})$ of the blanket can be represented by the dependence:

$$
\Delta P=\frac{A v^{n} \rho^{2} H}{d_{v} X}
$$

In this formula, $\mathrm{A}$ is a conversion factor $\left(\mathrm{A}=0.18 \times 10^{-5}\right)$; $\mathrm{n}$ is the exponent, depending on the heat flow regime. In engineering calculations, $n=1$ in the laminar mode and $v=0.2-$ $0.8 \mathrm{~m} / \mathrm{s}$; and $\mathrm{n}=1.4$ in transient mode and $\mathrm{v}=0.8-2.0 \mathrm{~m} / \mathrm{s}$ in laminar mode.

Taking into account the temperature of the blown heat carrying agent $(\mathrm{t})$, the hydraulic resistance could be calculated using the following formula:

$$
\Delta P_{t}=\Delta P\left(\frac{\mu_{t}}{\mu_{20}}\right)
$$

where $\mu_{20}$ and $\mu_{\mathrm{t}}$ are the dynamic viscosity coefficients at $20{ }^{\circ} \mathrm{C}$ and the actual temperature of the heat carrying agent.

\section{Discussion}

The dependences of the hydraulic resistance of a mineral wool blanket on its structural characteristics of the gas flow rate in the layer and its temperature are approximate, although acceptable in engineering calculations. Processing the results of empirical studies and using the conclusions of the theory of heat and mass transfer of capillary-porous bodies made it possible to develop a system of nonlinear equations that allow us to estimate the hydraulic resistance of a mineral wool blanket. For the convenience of engineering calculations, these dependencies are given in the nomographic form (Fig. 3).

The basic formula is taking into account the basic hydraulic resistance $\left(\mathrm{P}_{\mathrm{v}}\right)$, and coefficients depending on the parameters of the mineral wool blanket and technological factors:

$$
\Delta P=\Delta P_{v} \cdot K_{\rho_{T}} \cdot K_{\rho} \cdot K_{X} \cdot K_{C} \cdot K_{H} \cdot K_{d} \cdot K_{t} \cdot K_{u}
$$

Where $\mathrm{K}_{\rho \mathrm{T}}$ is a coefficient depending on the true density of the matrix substance (mineral fiber);

$\mathrm{K}_{\rho}$ is a coefficient depending on the medium density of the mineral wool blanket;

$\mathrm{K}_{\mathrm{X}}$ is a coefficient depending on the content of slugs;

$\mathrm{K}_{\mathrm{C}}$ - coefficient depending on the content of the binder;

$\mathrm{K}_{\mathrm{H}}$ - coefficient depending on the thickness of the blanket layer;

$\mathrm{K}_{\mathrm{d}}$ is a coefficient depending on the diameter of the fiber;

$\mathrm{K}_{\mathrm{t}}$ is a coefficient depending on the temperature of the heat carrying agent;

$\mathrm{K}_{\mathrm{u}}$ - coefficient depending on moisture content.

These coefficients were also calculated and shown at Fig. 3.

The moisture content of the blanket, with the introduction of a binder by spraying, is usually in the range $U=0.01-0.04 \mathrm{~kg} / \mathrm{kg}$. The presence of moisture up to $U=0.1 \mathrm{~kg} / \mathrm{kg}$ practically does not affect the hydraulic resistance, which is confirmed by the results of experiments, at speeds of air flow through the blanket up to $0.6 \mathrm{~m} / \mathrm{s}$.

With an increase in blanket moisture up to $6-10 \%$, which is characteristic of morally obsolete, but still functioning plants, the hydraulic resistance of the blanket to heat carrying agent passage increases sharply. At the same time, the relationship between blanket moisture and its hydraulic resistance is linear. These data must be taken into account when designing, 
operating, and optimizing the modes of heat treatment chambers of a mineral wool blanket with high humidity.

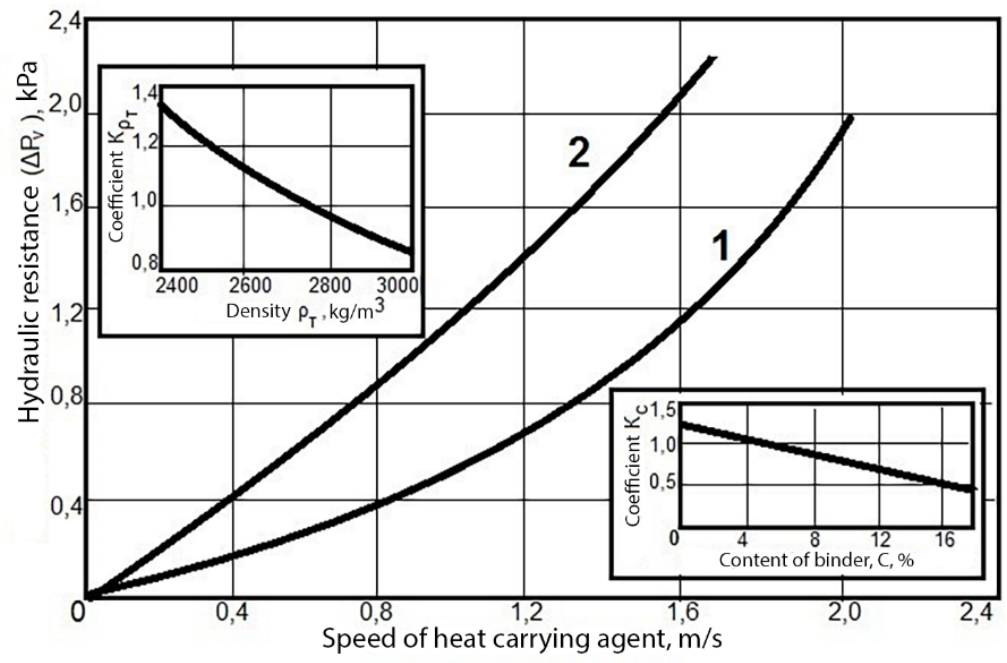

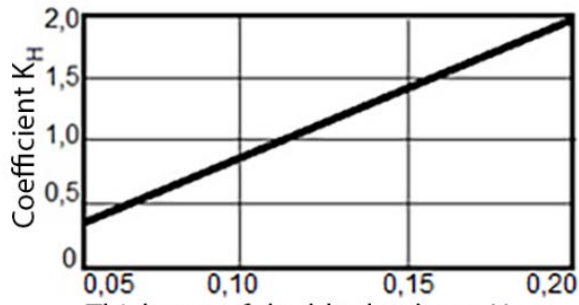

Thickness of the blanket layer, $\mathrm{H}, \mathrm{m}$
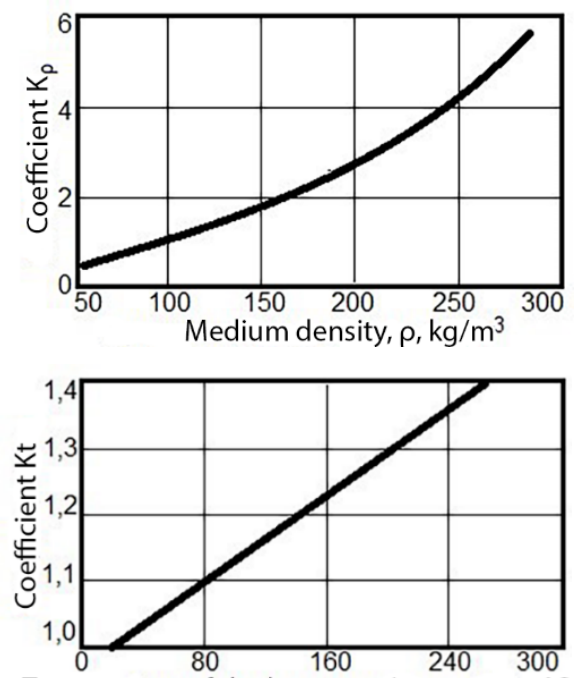

Temperature of the heat carrying agent, $\mathrm{t},{ }^{\circ} \mathrm{C}$
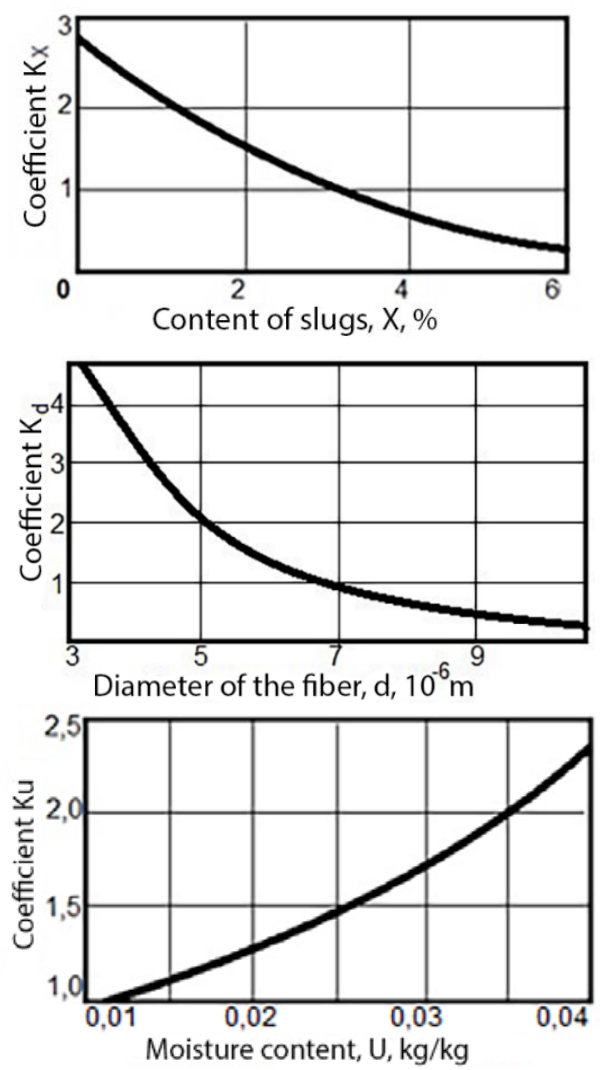

Fig. 3. Nomogram for determining the hydraulic resistance of a mineral wool blanket with a sprayed binder: 1 - linear structure blanket; 2 - volumetric oriented structure blanket 
Knowing the hydraulic resistance of a mineral wool blanket, one can evaluate the influence of technological parameters of heat treatment and, first of all, temperature and heat carrying agent speed on the properties of the resulting product. Experiments and analysis of a priori information show that the flow speed and uniform distribution of the heat carrying agent over the heated surface are the determining conditions for heating of the blanket, and, consequently, uniformity and completeness of curing of the binder in the mineral wool blanket. The completeness of the curing of the binder in the mineral wool blanket, due to the correctly selected parameters of the input of the heat carrying agent, allows reducing the temperature of the heat carrier by $10-15^{\circ} \mathrm{C}$, which determines the risk of fire of the binder in the mineral wool blanket.

The completeness of the curing of the binder in the mineral wool blanket, firstly, reduces the likelihood (or even danger) of toxic emissions from mineral wool products, which contributes to the creation of a favorable environment in rooms where mineral wool products are used to insulate floors, ceilings, roofs, and cellars. On the other hand, curing the binder to a level of at least $98 \%$ promotes the formation of strong contact zones, monolithic mineral wool fibers and improves the adhesion of the cured polymer and the surface of the glass (mineral fibers). This increases the operational stability of mineral wool products, and, consequently, the durability of the structures where these products are used.

\section{Conclusion}

Products made of mineral wool are one of the most common materials in facade and roof insulation systems, as well as heat and sound insulation of floor ceilings, etc. Reducing the dangers of harmful emissions (necessary for interior insulation) and increasing operational resistance (for use in external systems) is a factor determining the effective functioning of these systems.

The method of heat treatment of a mineral wool blanket proposed in the article, based on the provisions of the general theory of heat and mass transfer in capillary-porous bodies and formed as a result of analysis of experimental studies, allows us to solve the problem of choosing the optimal parameters of the process of motion of a heat carrying agent in a mineral wool blanket and determining the hydraulic resistance of this blanket.

Optimization of the heat treatment of a mineral wool blanket, on the one hand, allows to reduce energy costs for this process, and on the other hand, it reduces the risks of ignition of a mineral wool blanket when a hot heat carrying agent is sucked out. Moreover, the uniform distribution of the heat carrying agent flow along the plane of the blanket and the regulation of the heat carrying agent speed contribute to the most complete curing of the binder, which positively affects the properties of the products.

\section{References}

1. P.M. Zhuk, A.D. Zhukov. Ec. and Ind. of Russia. 4 (2018) 52-57.

2. N.P. Umnyakova. Vestnik MGSU, 4 (2010) 157-162.

3. E. Bobrova, A. Pilipenko, A. Zhukov. E3S Web. Conf. 91 (2019).

4. N.P. Umnyakova. Stroymetall, 4 (2009) 61-63.

A. Zhukov, T. Dovydenko, S. Kozlov, K. Ter-Zakaryan, E. Bobrova, E3S Web. Conf. 91 (2019).

5. $\quad$ N.P. Umnyakova. Zhilishchnoe stroitel'stvo 1 (2012) 30-33.

6. I.V. Bessonov A.V. Starostin, V.M. Oskina. Vestnik MGSU 3 (2011) 134-139.

7. V.I. Livchak. Ener. Sav. Mag. 5 (2002) 14-18.

8. Arquis E., Cicasu C. Proceedings of Eff. heat and sound ins. mat. in mod. constr. (2006) $18-21$. 
9. $\quad$ S.E. Shmelev. Build. Mat., 3 (2013), 7-9.

I. Gnip, S. Vaitkus, V. Kersulis, S. Vejelis. Mech. Time Depend. Mater. 16 (2012) 3146.

10. I.Ya. Gnip, S.I. Vaitkus. Build. mat. 11 (2013) 57-62.

11. A.D. Zhukov, T.V. Smirnova, D.B. Zelenshchikov, A.O. Khimich. Adv. Mat. Res. 838841 (2014) 196-200.

12. B.M. Rumyantsev, A.D. Zhukov, D.B. Zelenshikov, A.S. Chkunin, K.K. Ivanov, Yu.V. Sazonova. MATEC Web Conf. 86 (2016).

13. I.V. Bessonov, A.D. Zhukov, E.Yu. Bobrova. Hous. Constr. 7 (2015) 49-52.

14. A.D. Zhukov, Ye.Yu. Bobrova, D.B. Zelenshchikov, R.M. Mustafaev, A.O. Khimich. Adv. Mat., Struct. and Mech. Eng. 1025-1026 (2014) 1031-1034.

15. A.D. Zhukov, T.V. Konoval'tseva, E.Yu. Bobrova, E.A. Zinovieva, K.K. Ivanov. MATEC Web Conf. 25101016 (2018).

A. Zhukov, E. Bobrova, A. Medvedev, N. Ushakov, D. Beniya, A. Poserenin. Adv. in Intel. Sys. and Comp. 983 (2019) 828-838.

16. V.R. Hlevchuk, I.V. Bezsonov. NIISF (1998) 127-135.

17. B.M. Rumiantcev, A.D. Zhukov, E.Yu. Bobrova, I.P. Romanova, D.B. Zelenshikov, T.V. Smirnova. MATEC Web Conf. 86 (2016).

18. Yu.L. Bobrov. Mod. methods of qual. Contr. Probl. and their sol. (1985) 43-44.

A. Medvedev, E. Bobrova, A. Poserenin, E. Zarmanyan. MATEC Web Conf. 17003018 (2018).

A. Zhukov, A. Ter-Zakaryan, E. Bobrova, I. Bessonov, A. Medvedev, V. Mukhametzyanov, A. Poserenin. E3S Web Conf. 9102047 (2019). 